\title{
Opportunities and Challenges Faced by College Modernization Teaching from the Perspective of Digital Economy
}

\author{
Peng Yankun \\ College of Foreign Languages \& Culture, Chengdu \\ University \\ Chengdu, Sichuan, 610106
}

\author{
Jin Jing* \\ College of Economics and Management, Yunnan \\ Agricultural University \\ Kunming, Yunnan, 650201
}

\begin{abstract}
The digital economy with ICT as the core has a certain impetus to all aspects of society. The modernization education of "Internet + education" under the background of digital economy is the product of the development of educational technology to the stage of information technology, opening up a new era of modernization online education. Modernization teaching is a combination of technology and education, using technology to optimize education. As a modernization form of teaching that combines information and education, it fully embodies the characteristics of the Internet and the characteristics of the digital economy. This characteristic makes the modernization teaching of colleges and universities in the perspective of digital economy face both opportunities and certain challenges.
\end{abstract}

Keywords-digital economy; modernization teaching; opportunity; challenge

\section{INTRODUCTION}

In early May 2017, the British "Economist" cover article "The World's Most Valuable Resources" pointed out that data is the oil of the digital age (The Economics, 2017) [1]. In October 2017, the digital economy was written into the report of the 19th National Congress of the Communist Party of China. On November 7, 2018, Xi Jinping sent the message of congratulation to the Fifth World Internet Conference on the theme of "Creating a Digital World of Mutual Trust and Mutual Work---Building a Community of shared future in Cyberspace together", showing a large amount of information about the digital economy: What is the trend of world Internet development? How important is the digital economy? How do countries build a community of cyberspace destiny? For these questions, President $\mathrm{Xi}$ gave the latest answer: the world is experiencing a broader and deeper scientific and technological revolution and industrial revolution. Modern information technologies such as the Internet, big data, and artificial intelligence continue to make breakthroughs, and the digital economy is booming. The interests of all countries are closely linked. "To develop the digital economy and accelerate the digital industrialization." He pointed out that adding new kinetic energy to the development of the world economy urgently requires us to accelerate the development of the digital economy and push the global Internet governance

Correspondent Author: Jinjing, 1973. Associate professor. College of

Economics and Management, Yunnan Agricultural

University.Email:jinjing305@126.com. system to move in a more just and reasonable direction. As a big Internet country, China not only attaches importance to its own development, but also is committed to building a community of shared future in cyberspace, letting the Internet development benefit the people of all countries.

The modernization education of "Internet + education" in the background of digital economy is the product of the development of educational technology to information technology. In this modernization teaching mode, technology changes teaching, and teaching tests technology. [2] Technology and teaching are in harmony, modernization teaching is inseparable from technology, but we must understand that teaching technology is the teaching method and means.

\section{DIGITAL ECONOMY}

The digital economy emphasizes that data information and its transmission are a technical means of determining productivity and a representative of advanced productivity. This kind of technical means can penetrate into industrial production and labor in the service industry to form the socalled "Internet + ". In the production process that works together with other technical means, data information and the technical means of transmission determine the level of productivity. China Academy of Information and Communications Technology (2017) divides the digital economy into digital economy fundamentals (including electronic information manufacturing, information and communication, software services, etc.) and digital economy integration (Increased output of traditional industries caused by application of digital technologies to manufacturing, services, etc.) The development of the digital economy has gone through three stages. The first stage is the single-sector information economy stage of the 1940s; the second stage is the two-sector information economy stage of the 1980s; the third stage is the digital economy era relying on the network.

The historic, cosmopolitan, and even subversive digital economy is a new round of technological revolution and industrial transformation that affects all aspects of human society with network information technology as the main driving force. Its impact on human society is no less than the 
impact of the industrial economy on human society, greatly aggravating the process of globalization and accelerating the pace of human civilization.

Following the "Internet + " value creation law, the digital economy is becoming an important driving force for countries to grow new industries, upgrade traditional industries, and achieve inclusive growth and sustainable growth. China is a big economic country, a big Internet country, and a big digital economy. The development of the digital economy is also keeping pace with the times. According to the World Internet Development Report 2017 published by the Cyberspace Institute of China, 22\% of the world's GDP is closely related to the digital economy. According to estimates by China Academy of Information and Communications Technology, the total number of China's digital economy reached 27.2 trillion yuan in 2017, a nominal growth of nearly $20.3 \%$ yearon-year, accounting for $32.9 \%$ of GDP, up 2.6 percentage points year-on-year. In 2017, China's digital economy contributed nearly $70 \%$ of GDP. The contribution of China's digital economy to GDP growth is increasing, approaching or even surpassing the level of some developed countries [3]

From the perspective of the development of the international digital economy, major countries in the world have demonstrated a high attention to the development of the digital economy through a series of related strategies, such as: "Federal Cloud Computing Strategy of the United States, " Research and Development Plan of Big Data " Etc., the UK's "2015-2018 Digital Economy Strategy", "British Digital Economy Strategy", Japan's "e-Japan Strategy", "u-Japan Strategy" and so on. On the one hand, these countries have laid a solid development foundation by enhancing technological innovation and industrial capabilities. On the other hand, all countries have strengthened the application of digital technology and deepened the integration development. China and the United States are working hard to raise the level of education digitalization. The EU has upgraded its digital literacy to a national strategic level and implemented the "Digital Literacy Project" to enhance citizens' ability to use digital resources and digital tools and expand the demand for digital usage.

\section{MODERNIZATION}

Modernization is a process of "collecting great achievements". It is embodied in a rigorous multi-layered integration process of "mind, skill, management, and environment". With the emergence of modernization, all aspects of social culture have changed. The modernization penetrates into the political, cultural, and ideological fields of society and is expressed as a multi-level, multi-stage historical process.

Modernization can refer to the advanced social structure, and can also refer to the process of people's pursuit of experience renewal, technological progress, and scientific development, in order to achieve continuous optimization of social structure. Modernization is not only limited to industrial civilization, it has unlimited extension, and it is constantly being constructed and continuously developed. One aspect of modernization is the explosion of technology, which allows human thought to grow and pass at an alarming rate and quantity. The process of people constantly exploring modern information science and technology and creating an "Internet $+"$ society belongs to a modernized category. Modernization has its own inherent regulations. While realizing the modernization of technology and material level, it must adhere to humanism and take care of history and tradition. In other words, it has cultural roots and nationality.

\section{MODERNIZATION TEACHING PRODUCED BY THE DIGITAL ECONOMY}

Modernization teaching is the modernization of culture. The modernization of culture is the highest level of the modernization process. [4] History, tradition and culture are integrated into each other and become the objective identification and internal standard of the existence and uniqueness of a country or nation. Therefore, modernization is personalized, which means that each country's approach to personalization is different. The "Opinions on "Internet +" Actions issued by the State Council" is an important measure to promote the expansion of the Internet from the consumer sector to the production sector, accelerate the improvement of industrial development, enhance the innovation capability of enterprises, and build new advantages and new impetus for economic and social development. Under this situation, the rapid development of network information technology and the acceleration of economic globalization have brought unprecedented exchanges, mutual penetration and mutual integration of world politics, economy, culture and education. University teaching is also undergoing tremendous changes in response to the trend. In the middle and late 20th century, it was the era of the large-scale development and quantitative expansion of university education. The first half of the $21 \mathrm{st}$ century was the era of the connotative development and qualitative transformation of university education. [5] The most important part of university education is university teaching. Under the impetus of "Internet +", there are modernization teaching methods such as "Moocs", "Flipped classrooms and so on, liking "digital tuunami".

\section{OPPORTUNITIES FOR MODERNIZATION TEACHING IN COLLEGES AND UNIVERSITIES}

"Internet + Education" has opened up a new era of online education, making the boundaries between top universities and ordinary universities and other educational institutions increasingly blurred. It is an effective supplement to modern higher education, and has influenced many aspects of modern university teaching, such as curriculum design and development, teaching and organization, construction of teaching staff and so on. 


\section{A. Sharing and generalization of university's top educational resources}

The modernization teaching of colleges and universities produced under the background of digital economy is the product of the development of educational technology to the stage of information technology. It makes full use of multimedia technology to build a large-scale and open online education system through the Internet. As a modernization teaching form combining information and education, it fully reflects the characteristics of the Internet and embodies the characteristics of the digital economy, namely the sharing of activities and the generalization of activities.

The era of Internet and cloud platforms has enabled us to have all the means of educational resource sharing and modern teaching conditions. Institutions of higher education have broken their walls, and is open to each other and even is open to the whole society. All members of society can enjoy the best educational resources and enjoy the best teaching content through the Internet. The simple understanding is that anyone, at anytime, can learn knowledge anywhere. Modernization university teaching promotes the communion and symbiosis between society and education. The mutual opening of interuniversity teaching provides convenience for universities to learn from each other's strengths, which is conducive to the substantial improvement of the university's own teaching quality. This is not limited to domestic universities, but is the sharing and inclusiveness of the top-notch educational resources of world universities. Modernization teaching provides us with the opportunity to share advanced resources without going abroad, the opportunities for international exchanges between universities, and the opportunity to follow the footsteps of the world.

\section{B. Deepen the core idea of university education "Student, study"}

For a long time, the teaching methods of university education in China have adopted the traditional teaching methods of mechanical sluggishness and cramming. Most of the students passively accept knowledge. Under this teaching mode, students' participation is less and their enthusiasm is not high. Nevertheless, modernization teaching uses the new Internet technology to realize interactive online teaching without geographical restrictions. It can realize various interactions of multiple people on the Internet, stimulate students' interest and enthusiasm for learning, and can fully reflect the subjectivity of students. Students can make their own learning plans and set goal in a relatively relaxed and free environment based on their own hobbies and self-needs, translate their desire to acquire knowledge into an internal source of motivation, and experience the learning fun from voluntary initiative. This kind of learning embodies the original purpose, gaining knowledge as well as happiness, and also shows the core idea of university education "studentoriented, learning-oriented."

\section{The Challenges FaCED By COLLEGE MODERNIZATION TEACHING}

The digital economy follows the law of value creation of "Internet + ". Networking brings together digital technology resources and services to generate economic value by dramatically increasing application efficiency. The modernization teaching model of "Internet + " produced under this situation has been infected with some commercial atmosphere.

\section{A. Commercialization of knowledge}

The digital economy based on digital technology has significant features in terms of scale economy. Enterprises in the industrial economy era are affected by a number of factors, such as management capabilities, transaction costs, etc., the scale of enterprises is unlikely to expand indefinitely. In the era of digital economy, companies achieve scale economy through the externalities of the network. The "Internet + education" that originated from the digital economy certainly have this feature. The value of a network depends on the number of customers it connects to. The value of connecting to a network depends on the number of other people who are already connected to the network. [1] Some modernization teaching methods based on the Internet have led some companies to find business opportunities, and to provide them with funds and technical services. This makes the relationship between the market and the university more and more "close". The modernization teaching method has become a way of making money, and there has been a tendency of commercialization. The power of this market has made the university education itself lose the concept of people-oriented.

\section{B. Instrumentalization of Education}

While bringing convenience, technology often falls into the whirlpool that technology can do anything. Heidegger points out that "in the technical age, not people control technology but make people completely bound in the framework of technology, subject to the domination and control of technology, and consciously and unconsciously act according to the needs of technology. People are alienated by technology from existence [6] The modernization teaching methods produced under "Internet + Education" make teachers and students over-reliant on technology, and the ability of face-to-face communication between teachers and students is reduced. Teachers' excessive reliance on technology also reduces the ability of teachers to develop curriculum resources, and costs a lot of energy on technology. 


\section{CONCLUSION}

In the digital economy, a series of modernization teaching methods have been spawned. Modernization teaching integrates modern technology into the educational process and combines it with specific teaching in this process. Modernization teaching is a combination of technology and education, using technology to optimize education. Under this modernization teaching mode, on the one hand, we must see the sharing and generalization of the top educational resources of colleges and universities brought by the Internet and the cloud platform. On the other hand, we must realize the challenges faced by the modernization of colleges and universities in the digital economy: the commercialization of knowledge and the instrumentalization of education. We must adhere to the education concept of people-oriented, and guard against the victimization of knowledge commercialization to the value of education. All people should understand that technology and education are among each other. Technology is to serve education under the concept of "education-based, technology-used". [2] We must keep in mind: "The starting point of education is people, the actors are people, and the ultimate destination lies in educating people instead of creating artifacts [7].

\section{REFERENCES}

[1] Pei Changhong, Ni Jiangfei, Li Yue. Approach Digital Economy from the Perspective of Political Economics. Finance \&Trade Economics, 2018 (9): 5-22.

[2] G. Eason, B. Noble, and I.N. Sneddon, "On certain integrals of Zhang Chuansui, Hong Zhixiang. Reflections on the Philosophy of Technology of Moocs. [J], Course Education Research, 2017: 7-11.

[3] Lu Chuncong, Reflections on the Development of Digital Economy [J]. Cyberspace Strategic Forum, 2018, (3): 39-43.

[4] Xia Zhenkun. On Traditional Culture and China's Modernizatio [J]. Forum on Chinese Culture, 2005, (2): 100-105.

[5] Liu Guanhua, Dong Xiaoming. A Critical Analysis of MOOCs from the Perspective of Higher Educational Modernization[J], e-Education Research, 2016, (4): 69-75.

[6] Martin Heidegger. Martin Heidegger Anthology[M]. Shanghai: Shanghai Sumerian Press,1966: 33-34.

[7] An Tao, Li Yi. The Perspective of Educational Technology Theory from the Perspective of Philosophy of Technology [J]. Education Research, 2014 (4): 37-42. 